chlorophyll molecules, which acts as a light-gathering structure analogous to a lens, transferring and focusing the energy from a single photon to a photochemicallyactive electron sink. Kinetic studies, based on combinations of selective inhibitors of oxygen ovolution with the photochemically active site, have shown that the aggregate unit possesses approximately 2,500 chlorophyll molecules for each active oxygen-producing site. Losses in the energy transfers are compensated by an extension of half-life of the activated pigment molecules; an additional factor extending the stability of the excited pigments involves reaction with an associated electron carrier (probably cytochrome $f$ ) in a charge transfer complex. The entire process of photosynthesis may be viewed as an extension of the life-time of energy storage forms, from the activated singlet state of chlorophyll (half-life about $10^{-8} \mathrm{sec}$ ) to reduced pyridine nucleotide (half-life about $1 \mathrm{sec}$ ).

The problem of energy-production in certain autotrophic bacteria was broached by Dr. W. W. Umbreit (Rutgers University) and Dr. H. Lees (University of Manitoba). The inability of obligate autotrophs such as Thiobacillus thio-oxidans to grow with carbon sources other than carbon dioxide is unexplained since the organism possesses a full complement of enzymes for glucose metabolism, and converts ${ }^{14} \mathrm{C}$-glucose into cellular protein. Thiobacillus can be adapted to survive in the absence of earbon dioxide in a glucose medium under certain conditions but does not remain viable. The reduction of pyridine nucleotide for fixation of carbon dioxide by Nitrobacter does not appear to proceed by a direct pathway, since the redox potential for the oxidation of nitrite to nitrate is too high to permit a direct coupling of the two reactions. The initial electron transfor is to cytochrome $c$; reduction of pyridine nucleotide occurs by an energy-requiring reversed electron flow from cytochrome $c$, a reaction demonstrated previously in mammalian mitochondria and also reported for Escherichia coli.

Studies of oxidative phosphorylation in Mycobacterium phle $i$ wore described by Dr. A. F. Brodie (University of Southern California). The oxidation of malic acid by cytochrome-containing particles from this organism proceeds via two different enzyme reactions. The first is the typical pyridine nucleotide-linked dehydrogenase; the second path proceeds by a flavin-mediated reduction of a naphthoquinone. Depletion of particulate naphthoquinone by irradiation with long-wave ultra-violet light causes inactivation of oxidation and phosphorylation with a varioty of substrates. Restoration of activity on addition of synthetic and natural quinones revealed two sites of interaction with the electron transport system for pyridine nucleotide-linked substrates, and an additional site for succinate. The session on bacterial energetics was fittingly concluded by Dr. R. M. Hochster (Department of Agriculture, Ottawa) with a discussion of some unsolved prob. lems in this area. Major difficulties in assessing the efficiency of oxidative phosphorylation in microbial systems arise from the presence of high phosphatase activity and the existence of by-passes in the oxidative reactions.

The dynamics of carbohydrate metabolism in mammalian cells was discussed by Dr. G. R. Williams (University of Toronto) and Dr. E. Shrago (University of Wisconsin). by continuous monitoring of ${ }^{14} \mathrm{CO}_{2}$ roleased from carboxyl-labelled substrates by respiring liver mitochondria in vitro, it was possible to calculate the rate constants for utilization of intermediates of the tricarboxylic acid cycle. The rate constant for fumaric acid was considerably greater than that for succinic acid, suggesting that succinic dehydrogenase is a limiting component of the cycle. On the in vivo level, studies of enzymes in animals rendered diabetic by alloxan treatment revealed marked alterations in pathways of carbohydrate motabolism. The most dramatic chango was the marked incroase in activity of the soluble enzyme, phosphoenolpyruvic acid carboxykinase, in liver; since the increase was reversed by injection of insulin it would appear that this enzymo plays a major part in the endocrine regulation of gluconeogenesis.

Dissection of the mitochondrial oxidative phosphoryIation process into its partial reactions was presented by Dr. C. L. Wadkins (Johns Hopkins University). A protein of low molecular weight which catalyses an exchange reaction between adenosine diphosphate and adenosine triphosphate may bo extracted from liver mitochondria; simultaneously, the phosphorylation coupled to cytochrome $c$ oxidation is abolished, and may be restored by addition of the purified exchange enzyme to the depleted mitochondria. The exchange onzyme appears to corrospond in its action and properties to tho coupling factor III described by Green et al. Kinetic studies indicate that ferro-cytochrome $c$ combines at two sites on the exchange enzyme; interaction at one site is blocked by dinitrophenol, while azide or oligomycin $A$ prevents combinations at both sites.

Dr. W. Chefurka (Agricultural Research Institute, London) presented comparative data on the lability of phosphorylation reactions in mammalian mitochondria and insect sarcosomes. The rapid ageing of insect mitochondria is related to the rapid release of free fatty acids from mitochondrial lipids. The most sensitive indicator of the ageing process is the adenosine triphosphate cleavage occurring in the presence of dinitrophenol. The disappearance of the latter enzyme on ageing may be reproduced by in vitro addition of fatty acid.

The symposium was well organized by a local committeo under the chairmanship of Dr. K. P. Strickland. Fortunately, sufficient time was allowed for free discussion of the stimulating data and ideas presented in the formal papers. All present at the symposium were able to participate in several interesting functions concerned with nutrition, digestion, and the products of fermentation. Plans are under way to publish the papors in the Canadian Journal of Biochemistry.

W. C. MCMURRAY

\title{
OCEANOGRAPHY IN BRAZIL
}

\begin{abstract}
7 HE recent symposium on the oceanography of the western South Atlantic organized by the Brazilian Academy of Sciences (Rio de Janeiro, September 14-18) was an important step in the dovelopmont of tho investiga. tion of the sea in South America. For many years there has been an activo interest in oceanography in Brazil. Initially this manifested itself in the establishmont of the Instituto Oceanografico in the University of São Paulo and the acquisition of field stations, one at Ubatuba situated close to an inviting range of sub-tropical marine environments, and the other at Cananéia amidst an extensive mangrove swamp with its exciting scientific problems. These facilities encouraged an energetic interest in marine biology.
\end{abstract}

The Brazilian contribution to the symposium strongly reflected this initial interest but also showed how widely the field of work has since developed. Other laboratories have entered the field, and the papers pre. sonted included investigations of the Brazil current, of water movemonts noarer to the coast, the drift of littoral sediments, the production of organic matter, the biology of the plankton and benthos, and geophysical investigations of the sea-bod.

Delegates from Argontina and other South Amorican countries contributed accounts of similar investigations extending southwards to the waters of the Antarctic, and it was clear that an important aspect of a meoting such as this lay in bringing together for the first time 
scientists who often have to work in comparative isolation at widely separate places. A number of invited papers from abroad on the oceanography of adjacent regions or on more general problems of oceanography formed a background for the symposium.

The amount of resources devoted to marine science in Brazil is still not great, but as a visitor ono could not help being deeply improssed by what has been achieved on slendor resources and particularly by the great enthusiasm displayod by the younger sciontists. In all fiolds the awareness of the need for aiming at quality rathor than quantity of work stood out very clearly. There is a growing appreciation of the importance of oceanography to the country. The need to loarn more about available fisheries and to deal with the problems of defence of a very long coastline has stimulated interest in the Government and in particular in the Navy. Indeed, the Hydrographic Office has with the help of Unesco already almost completed the reconstruction of a research vessel, Almirante Saldanha, which will rank among the largest in the world. She will have an enormous potential for making much needed observations in the Brazil current, but it is to be hoped that such splendid facilities for making observations will not submerge the promising laboratory work which is also gaining impotus. Descriptive ocoanography in all disciplines must be paralleled with adequate theoretical and experimental work before we can expect to reach a real understanding of what happens in the sea. Brazil has the potential to undertake these investigations, and it is hoped that adequate support will be found for them.

Ronald I. CURRIE

\title{
APPLICATIONS OF MICROFILM READERS IN PETROGRAPHY
}

$\mathrm{M}$ ICROFILM recording of original documents is established practice, so also is the use of microfilm readors in their enlargement. In the more spocialized field of potrographic investigations of igneous, metamor. phic and sedimentary rocks, the use of microfilm readors in direct analysis of these materials may not be so generally known. In an article by Radco Kühnel, of the Institute for Minoralogy, Petrography and Geochemistry, Mining Academy, Ostrava, U.S.S.R. (English translation), entitled "Microfilm Reader in Potrography" (Jena Review, No. 3, 1964; VEB Carl Zeiss Jena, Jona (Saalo)), the potentialities of this adaptation of a modern technique are both lucidly explainod and convincingly illustrated.

Taking the ordinary thin section of a rock of conventional thickness about $30 \mu$, as normally examined undor a petrological microscope, and assuming that the averago sizo of the slide fits eomfortably within a $35-\mathrm{mm}$ microfilm frame (which according to European custom it should do), then the simple process of placing the thin section undor the microfilm reader results in a magnified natural image of the section, coloured if appropriate minerals are present, giving not only a clue to identification of at least some of the more easily recognized constituents, but equally to the microstructure and texture of both rock and minerals scrutinized. One initial advantage of this approach to a petrographic investigation is that the whole rock-slice, within the reador frame, can be seen as one field and in complete continuity, avoiding any interrup. tion in analytical assessment of mineral composition and microstructure sometimes occasioned by constantly changing horizontal and vertical orientations of those featuros in the normal course of microscopical examination. There is of course nothing new in projection of part or, if the original image is small enough, the whole of a thin section of rock or particlos by a petrological microscope and suitable optical bonch and illumination, on to an appropriate wall-scroen, especially for class-instructional or other demonstration purposes; but the microfilm reader, properly adapted, simplifies this operation.
Among advantages claimed by the author for microfilm reador technique, he mentions the following: ". . . measuremonts may be carried out on mm-graph paper, otc. ... for dotermining the absolute size of the individual grains ... the grain-bonding figure (average number of adjoining grains)". "As regards the texture, it is a simple mattor to ascertain the regularity of the spatial distribution as well as the orientation of the individual minerais. ... . In certain rocks (especially those rich in molanocratic constituents) it is possiblo to carry out modal determinations by means of a self-produced lattico. . . . Especially in sediment petrography it has given invaluable service in the investigation of the fine stratification, in post-sedimentary deformations, rhythmic precipitations, of gradation symptoms and other lithological phenomena." It is also possible to use this apparatus to explore thin sections of rocks in polarized light and with crossed nicols on the available projection area of the instrument, and with a more powerful lightsource if it is desired to project the image on to a wallscroen for instructional purposes. Another application of the microfilm reader is in photographic documentation of rock micro-structure and micro-texture. In this connexion the author briefly describes his work on 'negative micro-exposures', that is, on direct exposure of the section to photographic paper; he also indicates the possibility of producing direct micro-colour photographs of rocks and minerals by means of coloured reversal paper.

VEB Carl Zeiss Jena (C. Z. Scientific Instruments, Ltd., London, W.1) manufacture what they call a 'Dokumator Film Reader' which appoars to be ideal for the purposes doscribed here. In this apparatus the image appears on a $300 \mathrm{~mm} \times 390 \mathrm{~mm}$ screen of high reflective powor. An attachment for slides permits viewing of glass slides up to $50 \mathrm{~mm} \times 50 \mathrm{~mm}$ in area, but it is to bo noted that some special arrangements would have to be made if conventional British $75 \mathrm{~mm} \times 25 \mathrm{~mm}$ glass slides are involved; altornatively, the smaller foreign-type mounts might have to be used.
H. B. Milner

\section{SUB-UNITS OF THE CATALASE MOLECULE SEEN BY ELECTRON MICROSCOPY}

\author{
By Dr. R. C. VALENTINE \\ National Institute for Medical Research, Mill Hill, London, N.W.7
}

$\mathrm{C}$ ILEAR pictures of protein molecules are difficult to obtain with the electron microscope, although in size the molecules should be easily within its rosolving power. At present, negative staining is the most generally successful way of showing detail down to the molecular level. This is done by drying some dense but unreactive substance with the specimen; the relatively electron. transparent objects are outlined by the far more opaque 'negative stain'. When applied to protoin molecules, this technique works less well with some proteins than with 